\title{
श्रीअरविन्द की दश्टि में आध्यात्मिक कर्म का वैज्ञानिक निरूपण
}

राकेष वर्मा

\section{सारांश}

श्रीअरविन्द का जीवन एक कर्मयोगी की तरह रहा। उन्होंने साहित्य के माध्यम से समाज को अमूल्य निधि प्रदान की। उनका दृश्टिकोण पूर्णतः वैज्ञानिक था। श्रीअरविन्द आन्तरिक एवं बहिर्मुख दोनों तरह के कर्मों की आवष्यकता को स्वीकार करते हुए भगवत् कर्म को महत्ता देते थे। बाह्य जगत् को मनुष्य तभी जान सकता है जब वह आन्तरिक जगत् से परिचित हो और यह सत् कर्मों के द्वारा ही सम्भव है। सत् कर्म करते हुए अपने जीवन को पूर्णता तक पहुँचाना यहीं तो मानव जीवन का लक्ष्य है। श्रीअरविन्द एक द्रष्टा की तरह निरपेक्ष भाव में रहकर कर्म करने को प्रधानता देते है। उनके चिन्तन की मौलिकता कर्म सिद्धान्त की सीमाओं को स्पष्ट रूप से रेखांकित करती है। कर्म करना मानव का स्वभाव है। एक क्षण भी मनुष्य बिना कर्म के नहीं रह सकता। मनुष्य आज जहाँ कहीं भी है उसे आध्यात्मिक युग की ओर बढ़ना होगा। इसके लिए तर्क-बुद्धि को निर्मल करना होगा। इसके अभाव में वह चिंतनशील पशु है। भगवत्कृपा से यह सम्भव है अतएव मानव को एक न एक दिन आध्यात्मिक कर्म करते हुए श्रेष्ठता को वरन् कर चिर आनन्द स्वरूप की ओर अग्रसर होना ही है।

कूट शब्द. कर्मशक्ति, आध्यात्मिक शुद्धि, भगवत् अर्पित। 


\section{प्रस्थावना}

किसी भी कार्य के विस्तार की अपेक्षा उसकी पूर्णतः अधिक महत्त्व रखती है। 'कामों में, 'पूर्णता' के लिए अभीप्सा सच्ची आध्यात्मिकता है (श्रीमाताजी 2009a)।' मनुश्य के आध्यात्मिक होने की कसौटी इस बात पर निर्भर करती है कि वह अपने वैयक्तिक एवं वैण्विक जीवन से सम्बद्ध कार्यों में अध्यात्म के वैज्ञानिक प्रयोगों में कितनी तत्परता के साथ संलग्र है। मनुश्य के आन्तरिक मनोभाव पर उसके कर्म का आध्यात्मिक फल निर्भर करता है (श्रीअरविन्द 1996)। श्रीअरविन्द कहते है कि आकाष से बातें, संगमरमर के मंदिर तथा पाशाण प्रतिमा मानवीय हृदय की दाह को मिटाने में असमर्थ सिद्ध हुए हैं, इस कार्य के लिए मनुश्य को देष के भूखे, प्यासे नारायणों और दुर्बलविषणुओंकी सेवा में जुटने की प्रत्यक्ष भूमिका निभानी होगी(शर्मा, श्रीराम (1941)। कर्म का रहस्य अत्यन्त गहन है। कर्म के माध्यम से मनुश्य सम्पूर्ण सृश्टि में व्याप्त नारायण की अपने ढंग से सेवा करता है।4 अपने कर्मों द्वारा भगवान को अध्ध्यार्पित करना मानवीय प्रगति का सुनिष्चित साधन है। 'भगवान् के प्रति निवेदित किये गये कार्य के द्वारा ही चेतना सबसे अच्छी तरह विकसित होती हैश्रीमाताजी (2009b)।' कर्म जड़ एवं चेतन, दोनों ही तलों पर एक साथ सम्पन्न होता है, इसलिए वह पदार्थ और चेतना दोनों से सम्बद्ध होता है।

श्रीअरविन्द के अनुसार निर्हेतुक होकर किये गये कर्म से आध्यात्मिक षुद्धि होती है(श्रीअरविन्द 1996)। और चेतनात्मक विकास होता है। मनुस्मृति में उद्धत है कि कामना रहित होकर कर्म नहीं किया जा सकता(मनुस्मृति 2.4)। 'कर्म के क्षेत्र में कामना अनेक रूप धारण करती है। उनमें सबसे अधिक प्रबल रूप है अपने कर्मां के फल के लिए प्राणमय पुरूश की लालसा या उत्कण्ठा (श्रीअरविन्द 2003a)।' कर्मों के फल की कामना के अन्तर्गत धन, पद, प्रसिद्धि, विजय, सौभाग्य अथवा प्राणिक लालसाओं एवं भौतिक अभिरूचियों आदि के आग्रह आते हैं। इसके साथ ही किसी अभीप्सा
या सकंल्प की पूर्ति, अहंभावों की तुश्टि, उच्चतम् इच्छाओं या महत्त्वाकांक्षाओं की सफलता आदि मानवीय उत्कश्ठा के विशय हैं। कामना के ये विशय आन्तरिक एवं बाह्य जीवन की गतिविधियों से सम्बन्ध रखते हैं। श्रीअरविन्द कहते हैं, सुख-सम्पदा प्रदायी ये सभी कामनाएं 'समान रूप से कुछ ऐसे फंदे हैं जिनके द्वारा अहंभाव हमें बांधता है। सदा ही ये सुख-सन्तोश हमारे अन्दर यह भाव और विचार पैदा करके कि हम स्वामी और स्वतंत्र हैं हमें छला करते हैं, जबकि वास्तव में अन्ध 'कामना' की कोई स्थूल या सूक्ष्म, भली या बुरी मूर्ति ही-जो जगत् को प्रचालित करती है,- हमें जोतती ओर चलाती है। अथवा हमपर सवार होती और हमें कोड़े लगाती है (श्रीअरविन्द (2003a)।' अतएव मनुश्य को फल की सभी प्रकार की इच्छा का त्याग करके कर्त्तव्य कर्म अर्थात् निशकाम कर्म करना चाहिए। किन्तु मनुश्य के जीवन और उसकी मनोवृत्ति एवं मनोविज्ञान के आधार पर कामना रहित होकर कर्म करना असम्भव प्रतीत होता है। इस आधार पर मनुस्मृति की यह उक्ति कि कर्म के लिए कामना का होना आवष्यक है, पूर्णतः अस्वीकृत नहीं की जा सकती।

\section{कर्म की अवधारणा}

श्रीअरविन्द स्वीकारते हैं, 'कामना के बिना कर्म असम्भव है या कम से कम निरर्थक है एक आम भूल हैन्रीअरविन्द $(2003 \mathrm{~b})$ । $^{\prime}$ यह सिद्धान्त की कामना के अन्त के साथ ही कर्म की भी समात्ति हो जायेगी, अज्ञानी जगत् के लोगों के लिए आकर्शक हो सकता है किन्तु मनोवैज्ञानिक स्तर से ऊपर उठ चुके मुक्त-पुरूश के किसी काम का नहीं। संसार में ऐसे बहुत से कार्य सम्पत्न हो अपनी नियत गति से गतिमान है। उसकी इस गतिमें ऐसे बहुत से कार्य षामिल हैं जिसमें कामना का कोई हस्तक्षेप नहीं रहता। उसकी इस गति का कारण प्रकृति की सान्त आवष्यकता एवं स्वाभाविक नियम है। सामान्य रूप से मनुश्य कामना के वषीभूत होकर कार्य करता है फिर भी ऐसा कितनी बार होता है जब उसके कार्य किसी अभीप्सा या संकल्प से मेल नहीं खाते। तब 
उसके पीछे कोई उच्चतर नियम कार्य करता है। श्रीअरविन्द कहते हैं, 'कामना एक और प्रलोभन है जिसे प्रकृति ने अपने अवान्तर उद्देष्यों के लिए अपेक्षित एक विषेश प्रकार का राजसिक कर्म सम्पन्न करने के लिए चेतन प्राणियों के जीवन में महान् स्थान दिया है। परन्तु यह उसका एकमात्र इंजन नहीं है, यहाँ तक कि यह प्रधान इंजन भी नहीं है। जब तक कामना रहती है तब तक इसका एक बड़ा लाभ भी होता है: यह हमें जड़ता से उठने में सहायता पहुँचाती है और अनेक तामसिक पक्तियों का विरोध करती है, अन्यथा वे पक्तियाँ० कर्म को रोक ही देतीं(श्रीअरविन्द 2003b)। श्रीअरविन्द तीन तरह के कर्ता का निरूपण प्रकृति की त्रिगुणात्मकता के आधार पर करते है (श्रीअरविन्द (2008a)। तामसिक कर्ता का चित्त कर्म में नहीं लगता, अपितु कर्म करने में वह यान्त्रिक मन का उपयोग करता है। राजसिक कर्ता आसक्ति से युक्त होकर कर्म करता है और आतुरतापूर्वक उसे षीघ्र समाप्त करने की अभीप्सा रखता है। उसका मन अपवित्र एवं लोभ से ग्रस्त रहता है और वह परिणाम एवं पुरस्कार के लिए तीव्र लालायित होता है। सात्विक कर्ता समस्त आसक्तियों, अहंभावों एवं आवेषात्मक दुर्बलताओं से स्वतंत्र होता है। उसके कर्म उच्च, पुद्ध, निःस्वार्थ, उत्साह एवं दृढ़ निर्वेयक्तिक संकल्प से परिपूर्ण होते हैं। सात्विकता की चरमावस्था और उसके भी परे यह संकल्प एवं उत्साह आध्यात्मिक तपस् की स्वयं-स्फूर्त क्रिया का रूप रख लेते हैं। अन्ततः यही कर्म मानव-यंत्र में उच्चतम आत्मबल धारण करके साक्षात् भगवत् इच्छा से संचालित, विज्ञानमय मनीशा के सुनिष्चित कदम बन जाते हैं। श्रीअरविन्द मनुश्य को सम्बोधित करते हुए कहते हैं, 'तुम्हें अपने-आपको निम्न प्रकृति से ऊपर उठाकर उस प्रकृति में लाना होगा जो त्रिगुण के ऊपर है जो परमतत्त्व में, आत्मतत्त्व में प्रतिशिठत है। जब तुम्हें वह आत्मप्रसाद लाभ होगा तभी तुम मुक्त भागवत कर्म करने में समर्थ होगे (श्रीअरविन्द2008b)।'
साधारणजनों और योगियों-ऋशियों के कर्म एक समान नहीं होते। साधारण मनुश्य प्राण-सत्ता के साधारण हेतुओं यथा-धन, सफलता, षक्ति-सामर्थ्य, सामाजिक मान-मर्यादा, यष प्राप्ति आदि के लिए कर्म में निमग्र रहते हैं और इस तरह से उनके जीवन-व्यापार का संचालन होता रहता है। अपने स्वभाव एवं कर्म के परिणाम के अनुरूप उन्हें सफलता एवं असफलता मिलती है। श्रीअरविन्द कहते है, 'साधारण मानव जीवन में बहिर्मुख कर्म स्पश्ट ही हमारे जीवन का तीन-चौथाई या इससे भी बड़ा भाग होता है; केवल कुछ-एक असाधारण व्यक्ति ही- जैसे ऋशि-मुनि, विरले मनीशी, कवि और कलाकार,- अपने भीतर अधिक रह सकते हैं (श्रीअरविन्द 2003c)!' ये असाधारण व्यक्ति बहिर्मुखी कर्म की अपेक्षा आन्तरिक विचार एवं भाव के द्वारा स्वयं को अधिक गढ़ते हैं। श्रीअरविन्द आन्तरिक एवं बहिर्मुख दोनों तरह के कर्मों की आवष्यकता को स्वीकार करते हैं। पूर्ण जीवन की रचना आन्तरिक एवं बाह्य पक्षों के एकदूसरे से स्वतन्त्र होने पर सम्भव नहीं। आन्तरिक एवं बाह्य जीवन के पूर्ण रूप से एकीकृत होकर अपने से परे की किसी वस्तु की लीला में रूपान्तरित हो जाने पर, पूर्ण जीवन को मूर्त रूप मिलेगा।

\section{भगवत् अर्पित कर्म}

मानव जीवन जब भगवत् अर्पित होता है, तो प्राण-सत्ता के साधारण हेतुओं का स्थान प्रधानतया चैत्य एवं आध्यात्मिक हेतु लेने लगते है। जिससे व्यक्ति अपनी पूरी सामर्थ्य के साथ, अपनी संकीर्ण सीमाओं को तोड़कर भगवत् निमित्त कर्म करने में समर्थ बन जाता है। ऐसी दषा में व्यक्ति यदि अपनी चेतना या मनोभावों में विद्यमान-दुर्गुणों का निवारण कर ले तो भगवत् पक्ति उसकी प्राणिक-षक्ति एवं क्षमताओं का उपयोग करेगी और उसे अपने कार्य का माध्यम बनायेगी। श्रीअरविन्द कहते हैं, 'सामान्यतया मानव अभी आनन्दमय प्रकृति में आरोहण नहीं कर सकता; पहले उसे मन की अधिक ऊँची चोटियों पर स्थिर रूप में प्रतिश्ठित होना होगा तथा उनसे विज्ञान की ओर आरोहण करना होगा 
(श्रीअरविन्द 2003d)।' 'विज्ञान चिच्छक्ति का दिव्य ज्ञान-संकल्प है; यह प्रकृति-पुरूश की सामंजस्यपूर्ण चेतनता और क्रिया है (श्रीअरविन्द 2003e)।' पुरुष और प्रकृति के बीच का वास्तविक सम्बन्ध और सच्चा कार्य उसे विज्ञान की भूमिका में ज्ञात होता है क्योंकि वहाँ वे दोनों एकरस रहते हैं। अब भगवान माया के आवरण में नहीं रहते और समस्त कर्म उन्हीं के द्वारा होता है (श्रीअरविन्द 2003f)। 'विज्ञान में आरोहण, विज्ञानमय चेतना के यत्किंचित् अंष की प्राप्ति अवष्य ही मनुश्य की आत्मा को ऊपर उठा ले जाती है और उसके जगज्जीवन को ज्योति और पक्ति तथा आनन्द और आनंत्य की ऐसी महिमा में उन्नीत कर देती है तो हमारे वर्तमान मानसिक और भौतिक जीवन के पंगु कर्म तथा सीमित उपलब्धियों की तुलना में एक चरम-परम पूर्णता का असली स्थितिषील और क्रियाषील रूप प्रतीत हो सकती है (श्रीअरविन्द 2003g)।'

श्रीअरविन्द के अनुसार विज्ञानमय पुरूश में कर्म की इच्छा विद्यमान रहती है। उसकी इच्छा ज्ञान सम्मत् होती है, जिसे कार्यान्वित करने की पक्ति भी उसमें होती है। अज्ञान उसे न करने योग्य चीजों के लिए प्रेरित नहीं कर सकताश्रीअरविन्द (2005)। उसके कर्म स्पृहा रहित होते हैं। उसका आनन्द अध्यात्म सत्ता के घुद्ध आनन्द में निहित होता है। 'अनन्त एवं निरपेक्ष भगवान् ही विज्ञान के सब कार्यों का चिन्मय उद्भम, सहचारी तत्त्व, अनिवार्य गुण-धर्म, आदर्षमान, क्षेत्र और वातावरण है (श्रीअरविन्द 2003e)।' वस्तुतः वह परात्पर या अज्ञेय परब्रह्म जो विराट्, परम, सनातन एवं अनन्त है, समस्त कर्मां का स्वामी है।

अनन्त भगवान् ही सभी कर्मों के कर्ता हैं समस्त कर्मां के पीछे उन्हीं की सचेतन षक्ति कार्यरत है। सभी धर्मों को अर्थात् समस्त कर्त्तव्य कर्मों को मुझ में त्यागकर मात्र एक मुझ सर्वषक्तिमान् सर्वाधार परमेष्वर की ही परण में आ जा, तू षोक मत कर, मैं तुम्हें समस्त पापों से मुक्त
कर दूँगा (श्रीमद्रूगवद्रीता 18/66)। भागवत् पुरूश ने ऐसा आण्वासन देकर मनुश्य के सम्मुख उच्चतम जीवन का सर्वाच्च आदर्ष रख दिया है।

\section{निष्कर्ष}

श्री अरविन्द मानवीय मन का तीक्ष्ण दृश्टि से विष्लेश्ण करते है। उनकी लेखनी अतिमानस की गहराईयों तक जाती है। वे कर्म के द्वारा आरोहण को महत्ता देते है। मानसिक स्तर पर कर्म करने या उच्चतर इच्छा को कार्यान्वित करने में विरोध एवं असामन्जस्य की सम्भावना बनी रहती है। यहाँ पर आत्मा या प्रतीयमान पुरूश स्वयं को चरम-परम सत्ता या परम पुरूश से अलग समझता है। विज्ञान में आरोहण हो जाने पर, विज्ञानमय सत्ता की इच्छा भगवत् इच्छा के साथ समन्वित होगी, उनमें कोई अलगाव या विरोध नहीं रहेगा। कर्मासक्ति एवं फलाकांक्षा से वह मुक्त होगा, फिर भी कर्म और उसके परिणाम का आनन्द उसे मिलेगा। विज्ञानमय स्तर पर व्यक्ति 'सत्' की सत्ता में अधिशिठत होता है, जिससे वहाँ समस्त असंगतियाँ एवं विरोध विलीन हो जाते हैं। ऐसे में विज्ञानमय पुरूश द्वारा कृत कर्म भगवत कर्म या बहु में एक का कर्म बन जाता है, जिसका परिणाम चिर आत्नद के रूप में प्रकट होता है।

Rakesh Varma, Yoga and Health, Dev Sanskriti Vishwavidyalaya, Email rakesh.varma@dsvv.ac.in 
सन्दर्भ

मनुस्मृति 2.4. अकामस्य क्रिया काचिद् दृष्यते नेह कहिंचित, यद्यद्धि कुरूते किंचित तत् तत् कामस्य चेश्टितम्।

श्रीअरविन्द (1996). श्रीअरविन्द के पत्र भाग-2 व 3। अनुवादक चन्द्रदीप त्रिपाठी। पाण्डिचेरी-श्रीअरविन्द आश्रम। पृ. 175

श्रीअरविन्द (2003a). योग-समन्वय । अनुवादक जगन्नाथ वेदालंकार। पाण्डिचेरी-श्रीअरविन्द आश्रम। पृ. 104

श्रीअरविन्द (2003b). योग-समन्वय । अनुवादक जगन्नाथ वेदालंकार। पाण्डचेरी-श्रीअरविन्द आश्रम। पृ. 269

श्रीअरविन्द (2003c). योग-समन्वय । अनुवादक जगन्नाथ वेदालंकार। पाण्डिचेरी-श्रीअरविन्द आश्रम। पृ. 93

श्रीअरविन्द (2003d). योग-समन्वय । अनुवादक जगन्नाथ वेदालंकार। पाण्डिचेरी-श्रीअरविन्द आश्रम। पृ. 517

श्रीअरविन्द $(2003 e)$. योग-समन्वय । अनुवादक जगन्नाथ वेदालंकार। पाण्डिचेरी-श्रीअरविन्द आश्रम। पृ. 512

श्रीअरविन्द (2003f). योग-समन्वय । अनुवादक जगन्नाथ वेदालंकार। पाण्डिचेरी-श्रीअरविन्द आश्रम। पृ. 503-504

श्रीअरविन्द (2003g). योग-समन्वय । अनुवादक जगन्नाथ वेदालंकार। पाण्डिचेरी-श्रीअरविन्द आश्रम। पृ. 505

श्रीअरविन्द(2005). दिव्य जीवन । पाण्डिचेरी- श्री अरविन्द आश्रम। पृ. 958 श्रीअरविन्द(2008a). गीता-प्रबन्ध। पाण्डिचेरी- श्री अरविन्द आश्रम। पृ. 569

श्रीअरविन्द(2008b). गीता-प्रबन्ध। पाण्डिचेरी- श्री अरविन्द आश्रम। पृ. 131

श्रीमदूगवद्रीता 18/66 - सर्वधर्मान्परित्यज्य मामेकं परणं त्रज। अहं त्वा सर्वपापेक्यो मोक्षयिश्यामि मा पुचः।।

श्रीमाताजी (2009a). माताजी के वचन प्। पाण्डिचेरीश्रीअरविन्द आश्रम। पृ. 338

श्रीमाताजी (2009b). माताजी के वचन प्। पाण्डिचेरीश्रीअरविन्द आश्रम। पृ. 327

शर्मा, श्रीराम (1941). योगी अरविन्द घोश की वाणी । अखण्ड ज्योति। 3,11 । मथुरा- युग निर्माण योजना। पृ. 5

सिंह, शिवप्रसाद (2008). उत्तर योगी श्रीअरविन्द। इलाहाबाद- लोक भारती प्रकाषन। पृ. 296 